\title{
Are people in residential care entitled to receive rehabilitation services following hip fracture? Views of the public from a citizens' jury
}

Maria Crotty ${ }^{1,2^{*}}$, Emmanuel S. Gnanamanickam ${ }^{2,3}$, lan Cameron ${ }^{4}$, Meera Agar ${ }^{5}$, Julie Ratcliffe ${ }^{6}$ and Kate Laver ${ }^{1,2}$

\begin{abstract}
Background: Access to rehabilitation services for people living in residential care facilities is frequently limited. A randomised trial of a hospital outreach hip fracture rehabilitation program in residential care facilities has demonstrated improvements in mobility at four weeks and quality of life at 12 months but was not considered cost-effective by standard health economic metrics. The current study aimed to explore the general public's views on issues involved in the allocation of rehabilitation resources for residents of care facilities.

Methods: A citizens' jury comprising 13 purposively sampled members of the general public, representative of the South Australian age, gender and household income profile. The jury considered the questions "Should there be an investment of physical rehabilitation services in residential care for older people following a hip fracture? If so, what is the best way of providing this service (considering funding, models of service delivery and equity)?" Deliberations were in the context of a state-wide health reform program. The jury was conducted over two days with an experienced independent facilitator, addressing questions developed by a steering group of research academics and clinicians.

Results: The mean age of the citizens' jury members was 43 (range 26 to 61). Eleven members voted for investment in outreach hospital rehabilitation services in residential aged care. All jurors agreed a number of strategies in addition to investment should be implemented, including health care planning and decision making, increased emphasis on hip fracture prevention, training of aged care staff in rehabilitation and routine provision of hospital discharge summaries to families. The jury further advocated for an increased focus on rehabilitation in residential care, potentially through accreditation criteria, increasing health literacy of residents and families, implementation of age friendly environment strategies and improving connections of care facilities with community, hospital and tertiary services.

(Continued on next page)
\end{abstract}

\footnotetext{
* Correspondence: maria.crotty@flinders.edu.au

${ }^{1}$ Rehabilitation, Aged and Extended Care, College of Medicine and Public Health, Flinders University, GPO Box 2100, Adelaide, South Australia 5001, Australia

${ }^{2}$ NHMRC Cognitive Decline Partnership Centre, University of Sydney, Sydney, Australia

Full list of author information is available at the end of the article
}

(c) The Author(s). 2020 Open Access This article is licensed under a Creative Commons Attribution 4.0 International License, which permits use, sharing, adaptation, distribution and reproduction in any medium or format, as long as you give appropriate credit to the original author(s) and the source, provide a link to the Creative Commons licence, and indicate if changes were made. The images or other third party material in this article are included in the article's Creative Commons licence, unless indicated otherwise in a credit line to the material. If material is not included in the article's Creative Commons licence and your intended use is not permitted by statutory regulation or exceeds the permitted use, you will need to obtain permission directly from the copyright holder. To view a copy of this licence, visit http://creativecommons.org/licenses/by/4.0/ The Creative Commons Public Domain Dedication waiver (http://creativecommons.org/publicdomain/zero/1.0/) applies to the data made available in this article, unless otherwise stated in a credit line to the data. 
(Continued from previous page)

Conclusions: This citizens' jury representative of the general public recommends that regardless of dementia and frailty, people who live in residential care and are walking and fracture their hips should have access to hospital outreach rehabilitation and recovery services.

Keywords: Nursing homes, Dementia, Rehabilitation, Hip fracture, Citizens' jury

\section{Background}

Hip fractures are a common cause of loss of independence in older people and access to rehabilitation is inconsistent $[1,2]$. National guidelines on the management of people with hip fracture suggest that those who live in residential care facilities should not be excluded from accessing rehabilitation services but in practice there is inconsistent access even for those who were walking prior to hip fracture [3, 4]. Hospital and community rehabilitation services who often operate in an environment of fiscal constraint, may not allocate rehabilitation services to people living in residential care facilities where the benefits are uncertain.

People who live in residential care facilities and fracture their hip often have comorbidities of dementia [5] and frailty [6]. They suffer particularly poor outcomes with high mortality rates and dramatic decreases in mobility $[7,8]$. A retrospective study examining US Medicare data found that amongst people living in residential care facilities who were independently mobile prefracture, only $21 \%$ survived and regained their prefracture independence at a median of 4 months [9]. It is unclear whether these poor outcomes are the expected consequence of a significant morbid event occurring in a frail group or whether they resulted from a failure to access adequate recovery treatments.

The effectiveness of hip fracture rehabilitation for people living in residential care facilities is uncertain, in part because people from residential aged care facilities are not included in trials [10]. Similarly, evidence for people with dementia is scant. Multi-disciplinary rehabilitation services can improve outcomes for older people after hip fracture [11] and a co-ordinated program has been recommended [12]. Effectiveness has also been observed among those individuals with dementia [13] and providing organised rehabilitation after a hip fracture appears to increase the likelihood that an individual will recover independence [14]. Unfortunately, despite $40 \%$ of people with hip fractures also having cognitive impairment, very few trials $(n=7)$ have included people with dementia in examinations of the effects of rehabilitation after hip fracture [15]. One of the few randomised controlled trials examining hip fracture rehabilitation in aged care residents was completed in South Australia [16]. The trial recruited 240 residents of aged care facilities who were walking prior to hip fracture, almost all of whom were living with dementia. The trial examined the impact of a hospital outreach rehabilitation program. While gains in mobility were achieved at 4 weeks they were not sustained and despite small gains in quality of life sustaining at 12 months the program could not be considered cost effective using conventional health economic modelling [16].

As in many jurisdictions around the world, South Australia engaged in a health reform process in 20152016 [17] which involved reducing hospital infrastructure (including inpatient rehabilitation hospital beds), implementing out-of-hospital models of care (e.g. home rehabilitation and tele-rehabilitation) with the objective of achieving shorter inpatient stays and reviewing access criteria for services. During rapid health reform processes there is significant risk that the voices and preferences of people living in residential aged care, their carers and the general public are not heard. This led on to the citizens' jury which was convened to explore issues involved in the allocation of rehabilitation resources for residents of care facilities. The aforementioned local trial results including information on cost effectiveness were available for discussion at the jury.

Citizens' juries are a method for engaging members of the public in health policy decision making. Citizens (acting as jurors) deliberate pre-determined research questions and in doing so provide the perspectives of the broader public. Within health, citizens' juries have been convened to address ethical issues, priority setting, policy, environmental health and wellbeing and have been conducted predominantly in Canada, USA, UK, Australia and New Zealand [18]. The purpose of recommendations stemming from the jury is to help policy makers understand the sentiments of the public and juries are considered particularly useful for addressing value-laden and controversial issues facing governments. Policy makers and health system planners in Australia have supported the use of citizens' juries and they have been used to inform priorities and make recommendations for a number of health interventions including adolescent vaccination programs [19], surgical management of obesity [20], emergency department treatment [21] and taxing of soft drinks [22]. With respect to care for older people, a citizens' jury conducted in the UK 
examined priorities for development of dementia care services [23] and another examined introduction of consumer directed care in residential care in Australia [24].

\section{Methods}

This paper discusses the process and results of the citizens' jury that addressed questions on providing rehabilitation for people living in residential care who fractured their hip. The jury were asked to consider the benefits and costs of rehabilitation in the context of the widely publicised state-wide health reform program [17] and constrained resources. The questions posed to the jury were: Should there be an investment of physical rehabilitation services in residential care for older people following a hip fracture? If so, what is the best way of providing this service (considering funding, models of service delivery and equity)? This study was approved by the Social and Behavioural Research Ethics Committee at Flinders University (project \# 7141).

\section{Overview}

An overview of the jury process is shown in Fig. 1. A steering group consisting of research academics and clinicians was formed and was responsible for developing and refining the question ('charge') for the jury and developing the program of speakers and topics. The jury took place over 2 days (Saturday/Sunday) in 2016. A purposively sampled group of members of the public were appointed to the jury following informed consent to participate and were presented with the question. On the first day the jury had the opportunity to listen to a variety of expert witnesses who provided the jury with background information to assist their decision making and presented their views on the problem. The second day was dedicated to deliberation and the formulation of recommendations. The two-day jury process was facilitated by an experienced independent facilitator.

\section{Participants ('jurors')}

Participants were recruited from the general public in South Australia through a market research company. The criteria for selection of jury members were that they should be representative of the general population in South Australia in terms of age, gender and household income. Those currently working in the field of health and aged care were excluded and so were those who were a primary carer for someone with dementia. The market research company used a list of verified landline and mobile phone numbers to source participants. Eligibility of the participants, relative to the criteria, was determined by short telephone survey.

\section{Speakers ('expert witnesses')}

Expert witnesses identified by the steering group included medical experts on palliative care, rehabilitation and hip fracture, families of people who lived in residential care and had suffered a hip fracture describing their experience, providers from residential care who explained staffing and funding issues, an expert on ethical decision making and a health economist discussing issues relating to efficiency and equity in the allocation of scarce health care resources $[25,26]$. The local trial results were presented demonstrating limited cost effectiveness of a hospital outreach multi-disciplinary rehabilitation intervention delivered in residential care for residents recovering from a hip fracture. The tensions between end of life care and maintaining function and quality of life in residential aged care facilities were

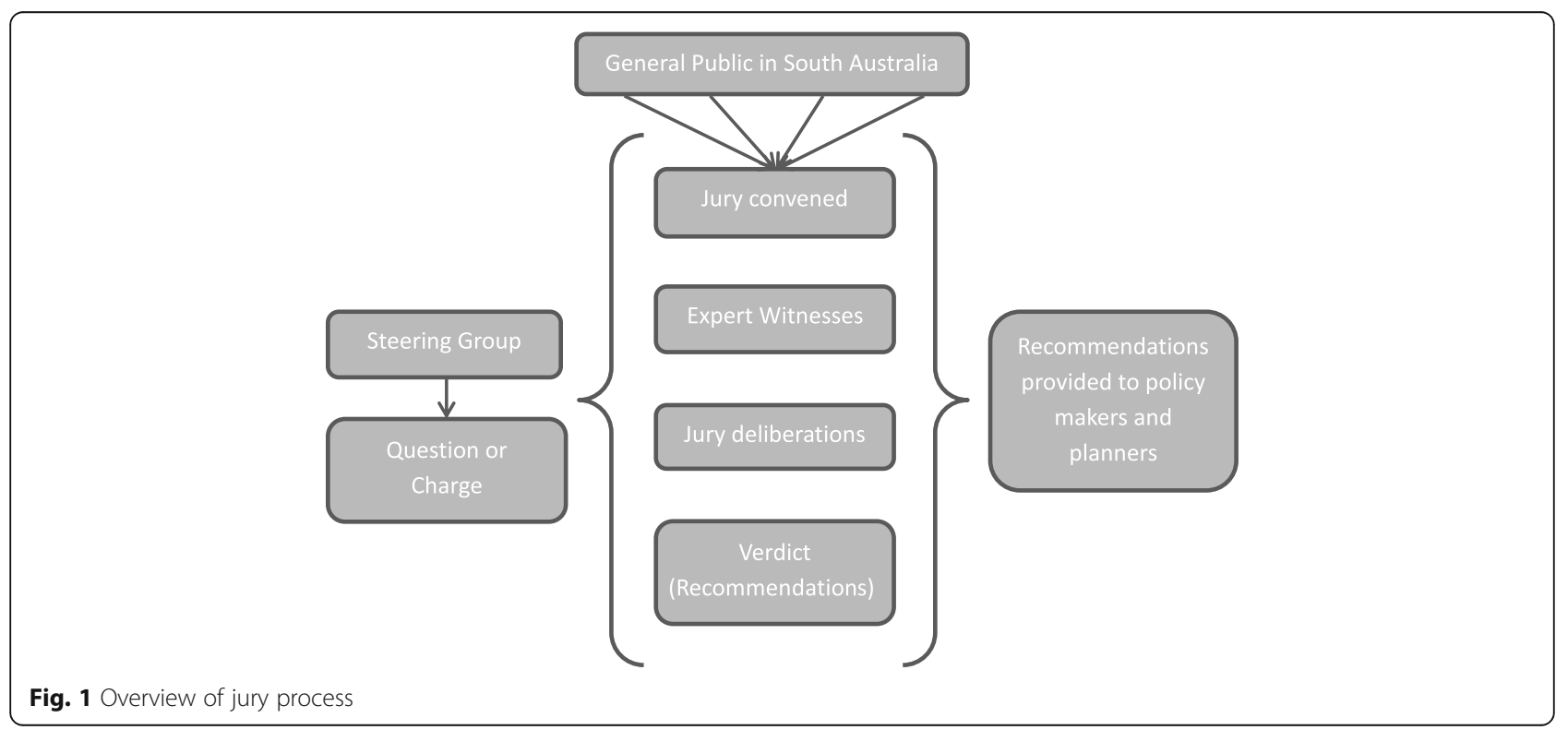


discussed. Jurors were able to interact with the witnesses in dedicated question times and then discuss the issues as a group. The jurors considered the issues in the context of end of life care and quality of life in people with dementia and the health economist and palliative care expert provided advice regarding this. The jury then deliberated and delivered their verdict (answers to the questions) [27].

\section{Data collection and analysis}

The information provided by the witnesses, the questions raised by the jury members and the intermediary and final presentation of recommendations of the jury together formed the data for this paper. Audio recordings of the formal discussions of the jury were collected. The final recommendations of the jury were presented by one of the jury members and video recorded. A thematic analysis of both the intermediary and final recommendations of the jury was conducted to draw out the themes that underpinned the reasoning behind the jury's recommendations [28]. Jurors were given the opportunity to evaluate the entire process for satisfaction, amount of information, quality of witnesses and bias in information and guidance provided.

\section{Results}

\section{Participants}

Fourteen members of the public were recruited to the jury although one member withdrew before the weekend of the jury. The final jury consisted of 13 participants with a mean age of 43 years and ranging from 26 to 61 years of age (Table 1).

\section{Jury recommendations}

The jury recommendations are presented in Table 2 and Table 3. For the question on investment in physical rehabilitation services in residential aged care following a hip fracture (Table 2), 11 jury members voted that there should be an investment while the two remaining members voted no. Both those voting 'no' and those voting 'yes' identified similar issues that needed to be considered by policy makers (elaborated in the next section).

All jurors agreed that investment in rehabilitation alone was not the answer and that a number of strategies should be implemented ('buts'). This included the need for appropriate health care planning and decision making, through the use of advance care planning and educating and supporting families to make early decisions, starting prior to the surgery, on post fracture care including whether surgery would lead to the best outcome for the person. The jury recognised the high incidence of hip fracture in residential care and the burden associated with this and thus recommended an increased emphasis on hip fracture prevention. The jury also felt
Table 1 Characteristics of Jury members

\begin{tabular}{|c|c|}
\hline Characteristic & \multirow[t]{2}{*}{ N (\%) } \\
\hline Mean age (SD) & \\
\hline 18-34 year olds & $5(38)$ \\
\hline $35-54$ year olds & $4(31)$ \\
\hline 55-70 year olds & $4(31)$ \\
\hline \multicolumn{2}{|l|}{ Gender } \\
\hline Male & $7(54)$ \\
\hline Female & $6(46)$ \\
\hline \multicolumn{2}{|l|}{ Paid Work } \\
\hline Yes & $10(77)$ \\
\hline No & $3(23)$ \\
\hline \multicolumn{2}{|l|}{ Annual Income } \\
\hline$<\$ 50,000$ & $5(38)$ \\
\hline$\$ 50,000-\$ 100,000$ & $4(31)$ \\
\hline$>\$ 100,000$ & $4(31)$ \\
\hline \multicolumn{2}{|l|}{ Highest educational qualification attained } \\
\hline Primary School & $1(8)$ \\
\hline High school & $4(29)$ \\
\hline Technical College, or trade certificate or diploma & $6(32)$ \\
\hline University or other tertiary institute degree & $2(14)$ \\
\hline \multicolumn{2}{|l|}{ Born in Australia } \\
\hline Yes & $11(85)$ \\
\hline No & $2(15)$ \\
\hline
\end{tabular}

that staff within aged care facilities should be provided with more training in rehabilitation skills; this would complement the work provided by specialist rehabilitation services and be beneficial for resident wellbeing more broadly. The jury emphasised the importance of good communication (between the hospital and both the residential care facility and family members) and suggested that hospitals routinely provide the discharge summary and information on optimal post hip fracture care to a family member in addition to aged care facility staff; this is not current practice in Australian hospitals where the discharge summary is provided to aged care facility staff. The reasoning behind this was that if family members had more information about optimal care, they may be able to play a role in the rehabilitation of the person by encouraging mobility and be better placed to advocate for required services.

Table 3 presents a summary of the jury's recommendation on the best models to provide the rehabilitation services. Included are the jury's recommendations on various themes of the rehabilitation service such as location, type, decision making, funding and other issues.

In addition to the recommendations on the two questions that were posed to the jury, the jury identified 
Table 2 Question 1 - Should there be an investment of physical rehabilitation services in residential care for older people following hip fracture?

\begin{tabular}{ll}
\hline Verdict votes & Buts (common to both the yes and no groups) \\
\hline 0 voted yes & - There is need to invest in other options such as good advance health care planning, family education, ethical decision making \\
0 voted no & and that surgery may not be the best option \\
11 voted 'yes, & - There is need to invest in prevention to reduce falls/injuries \\
but...' & - Transparent eligibility criteria are essential - not everyone should receive rehabilitation, for example people not walking prior to \\
2 voted 'no, & hip fracture \\
but...' & - Training for residential care staff on how to promote independence \\
& - An opt out option of treatments should be available to everyone \\
& - Funding for residential care should reward functional gain, not dependency \\
& - The rehabilitation program provided should be flexible. For example, a strong psycho-social focus may be needed rather than a \\
& physical focus \\
& - Provide discharge summary to family member prior to return to residential care to assist with transition
\end{tabular}

additional strategies that would complement the recommendations. The jury advocated for:

1. An increase in rehabilitation focus in residential care for people returning from hospital potentially through accreditation criteria supporting this approach.

2. Increasing health literacy of residents/families in order to improve understanding of hip fracture, rehabilitation services, advance care planning and decision making.

3. Implementing strategies that enable age friendly environments, encouraging people to keep active and remain socially connected

4. Improving connections to the local community including a schools and community groups, hospitals with geriatricians and specialist therapists.

\section{Jury reasoning}

The data from the jury's deliberations were analysed to evaluate the values and reasoning that underpinned their recommendations. Equity was an important value of the deliberations. For the question on investment in rehabilitation service after a hip fracture, jury members felt that people who had worked hard and contributed to society all their lives should not be denied access to rehabilitation in part because they were residing in a nursing home. Conversely, those $(n=2)$ who opposed the investment expressed concerns about the relative cost ineffectiveness of the programme in comparison with other potential investments for scarce dollars and felt that the program should not focus on physical rehabilitation alone, but holistic rehabilitation instead.

Three themes were important in the reasoning: person centred care, quality of care and economic considerations. These three themes were overlapped in some deliberations and underpinned each other in other deliberations.

Person centred care underpinned several aspects or characteristics of the rehabilitation service detailed in Table 3. Values such as familiarity, comfort and dignity underpinned the recommendation that the care home is

Table 3 Question 2 -what are the best models

\begin{tabular}{|c|c|c|}
\hline $\begin{array}{l}\text { Characteristics of the } \\
\text { rehabilitation service }\end{array}$ & Recommendation & Voting \\
\hline Location & Best venue for rehabilitation was in the residential care facility & All agreed \\
\hline Type & The investment should be in the form of an in-reach service & 12 jurors agreed. 1 juror had reservations. \\
\hline Attributes & $\begin{array}{l}\text { Flexibility, regular review, tailored to individual, capped in length, } \\
\text { multidisciplinary, holistic, respectful and equitable }\end{array}$ & All agreed \\
\hline Decision on content & $\begin{array}{l}\text { Option 1: Decision making should be shared between a rehabilitation } \\
\text { 'expert or broker' and the resident and/or family to ensure informed } \\
\text { choice. } \\
\text { Option 2: There should be a menu of a few set options which families } \\
\text { could select from e.g. physical therapy, geriatrician, dietician }\end{array}$ & $\begin{array}{l}11 \text { jurors preferred option } 1 \text { and } 2 \text { jurors } \\
\text { preferred option } 2\end{array}$ \\
\hline $\begin{array}{l}\text { Workforce } \\
\text { investment }\end{array}$ & $\begin{array}{l}\text { There should be an investment in up skilling residential care workers in } \\
\text { rehabilitation principles and practice }\end{array}$ & All agreed \\
\hline $\begin{array}{l}\text { Communication and } \\
\text { information }\end{array}$ & $\begin{array}{l}\text { Better communication between the discharging hospital and the } \\
\text { residential care facility }\end{array}$ & All agreed \\
\hline Funding & $\begin{array}{l}\text { Option 1: Government funding shared between Australian and State } \\
\text { governments } \\
\text { Option 2: State government } \\
\text { Option 3: Australian government }\end{array}$ & $\begin{array}{l}9 \text { jurors preferred option } 1,2 \text { jurors option } 2 \text {, one } \\
\text { juror option } 3 \text { and } 1 \text { juror said that they did not } \\
\text { know }\end{array}$ \\
\hline
\end{tabular}


the best location for the service. Patient centric values also underpinned shared decision making for service provision and highlighted communication and information sharing as a key component of the service. This theme also underpinned quality of care, one of the other two overarching themes from the data. Several ethical and quality of care aspects were commonly discussed by jurors. These include equipping of carers, communication and information, shared decision making and care planning that is patient centric, additional approaches to complement the service such as falls prevention, access to a rehabilitation mediator, multi-disciplinary holistic care and regular patient centric review of care provided.

The economic considerations that formed the basis for the recommendations included optimal use and allocation of resource use, the government's responsibility for the provision and funding of care for this vulnerable population group and the need to include a programme of recovery after surgery.

Data from the evaluation surveys for jurors showed that $69 \%$ were very satisfied and $31 \%$ were satisfied with the overall process. All participants were either satisfied or very satisfied with the background information provided, the expert witness presentations and the deliberations.

\section{Discussion}

Demographic changes associated with aging are associated with an increasing demand for long term residential care and maintaining quality of life in this setting is likely to involve access to rehabilitation to preserve function particularly after illness. The world report on ageing and health [29] calls for action in enabling older people to access rehabilitation services. Against a backdrop of high and growing demand for rehabilitation services, there is uncertainty about "the return on investment" of providing these services to people living in residential care nearing the end of life. Despite being presented with information on the low "return on investment" by a health economist, the majority of jurors favoured the provision of rehabilitation services to people who were old, at the end of life and frequently diagnosed with dementia, based on the principles of equity and maintaining quality of life. The citizens' jury recommendations emphasised choice, access and family involvement. Concerned that without rehabilitation, a frail older person would find it difficult to recover their ability to walk the jury members generally favoured clear criteria and judicious allocation of programs to those who were likely to recover walking and only where appropriate the provision of palliation.

The findings confirm other work showing that recovery and rehabilitation services are highly valued by members of the public and consumers of health services.
Great importance is placed on maintaining the ability to walk and many health service consumers believe that maintaining walking is strongly associated with quality of life [30]. Even in the very old, a discrete choice experiment involving families and patients with recent experience of hip fractures found that all participants including those from residential care disagreed with the statement 'I would prefer to go into a wheelchair now and forget about walking' and they were prepared to suffer moderate discomfort to recover walking [31].

The proportion of people living in residential care facilities prior to death varies across countries. About one fifth of older people (65+) in England and Wales [32] live in residential aged care prior to death while in Australia this proportion is approximately one third of all deaths among older people. There have been calls to treat hip fracture as a trigger for an "end of life" model of care [33] and in Australia residential aged care plays an important role in end of life care. Whilst acknowledging the importance of advance directives this jury felt that care which promoted recovery from hip fracture in a residential care setting was appropriate.

These findings have implications for policy makers designing funding models for people living in residential care. Treating people with hip fractures requires shared decision making; planning and coordination of surgical, anaesthetic, medical, rehabilitation, nursing and social work services across a range of care settings some of which are funded by the Australian national government and the others by the state governments. People who live in residential care access services in a different way to those living in the general community and they currently access substantially less rehabilitation services. It could be argued that once a decision has been made "to fix the hip" by operating, the older person should be offered various levels of support with recovery (including rehabilitation) to ensure an effective treatment outcome is achieved. While the cost of surgical treatment of a hip fracture can be between AU\$20,000 and AU $\$ 34,000$, without some post-operative investment in physiotherapy and nutrition services to promote recovery, a patient may be at increased risk of frailty, falls and re-fracture [34].

Research evaluating health services for older people receives relatively little funding relative to other health conditions [35]. Although our jurors were relatively young (ranging from 26 to 61 years) they showed a high level of support for investment in care of older people in residential care settings. Application of citizens' jury methodology to assist with prioritisation of research funding (within a context of scarce resources) would be a useful approach for funding bodies to understand research priorities of members of the public and assist with making decisions about allocation of funds. 
The analysis of the recommendations from the citizens' jury in conjunction with a qualitative analysis of the reasoning underpinning the recommendations reveals the value of a citizens' jury process. It provides critical information to support the future involvement of members of the general public in such processes to informing policy and decision making. The jury members were able to formulate informed recommendations based on the detailed and complex information provided to them through the witnesses (experts). While some of the recommendations such as patient centred care are already part of guidelines e.g. in Scotland [36] jury members called for stronger connections between aged care, community and hospitals suggesting that intersectoral integration is a high priority.

\section{Conclusions}

This citizens' jury recommends that regardless of dementia and frailty, people who live in residential longterm care and are walking and fracture their hips should have access to hospital outreach rehabilitation and recovery services. Whilst these reasoned views mirror to some extent existing recommendations and guidelines on the provision of rehabilitation care in residential care (e.g. NICE Hip Fracture Guidelines), they also confirm that a representative group of the general public supports investment in mobility and quality of life even when people are living in institutions.

\section{Acknowledgements}

We wish to acknowledge the jurors who participated and the expert witnesses who presented to the jurors. We wish to thank people who advised on the project who had a lived experience of hip fracture, receiving aged care or rehabilitation services or caring for a family member receiving such services.

\section{Authors' contributions}

Professor Maria Crotty conceptualised the study, obtained funding, oversaw the project, interpreted the data and drafted the manuscript. Dr. Emmanue S Gnanamanickam assisted with the operations of the jury, led the data analysis and assisted with writing the manuscript. Professor lan Cameron was involved in designing the study and research questions, interpreting the data and revising the manuscript. Professor Meera Agar contributed to the design of the study, attended the jury, interpreted the data and revised the manuscript. Professor Julie Ratcliffe was involved in designing the study and research questions, attended the jury, assisted with analysis and interpretation of the data and revising the manuscript. Dr. Kate Laver was involved in designing the research project, recruiting participants and collecting data, analysing data, interpreting data and revising the manuscript. The author (s) read and approved the final manuscript.

\section{Funding}

This study is supported by funding provided by the National Health and Medical Research Council (NHMRC) Partnership Centre on Dealing with Cognitive and Related Functional Decline in Older People (grant no. GNT9100000). The contents of the published materials are solely the responsibility of the Administering Institution, Flinders University, and the individual authors identified, and do not reflect the views of the NHMRC or any other Funding Bodies or the Funding Partners. The funding partners played no role in the design, execution, analysis or interpretation of the data, or preparation of the manuscript for the study.

\section{Availability of data and materials}

All data generated or analysed during this study are included in this published article [and its supplementary information files].

Ethics approval and consent to participate

This study was approved by the Social and Behavioural Research Ethics Committee at Flinders University (project \# 7141).

\section{Consent for publication}

Non-identifiable descriptive data only is presented in this paper. All participants were aware and consented to non-identifiable information to be included in a publication.

\section{Competing interests}

The authors declare that they have no competing interests.

\section{Author details}

${ }^{1}$ Rehabilitation, Aged and Extended Care, College of Medicine and Public Health, Flinders University, GPO Box 2100, Adelaide, South Australia 5001, Australia. ${ }^{2}$ NHMRC Cognitive Decline Partnership Centre, University of Sydney, Sydney, Australia. ${ }^{3}$ Health Economics and Social Policy Group, Australian Centre for Precision Health, School of Health Sciences, University of South Australia, Adelaide, Australia. ${ }^{4} \mathrm{~J} o \mathrm{hn}$ Walsh Centre for Rehabilitation Research, Faculty of Medicine and Health, University of Sydney, Sydney, Australia. ${ }^{5}$ IMPACCT (Improving Palliative, Aged and Chronic Care through Clinical research and Translation) Centre, Faculty of Health, University of Technology Sydney, Ultimo, Australia. ${ }^{6}$ Health Economics and Matthew Flinders Fellow, College of Nursing and Health Sciences, Flinders University, Adelaide, Australia.

Received: 11 February 2020 Accepted: 30 April 2020

Published online: 12 May 2020

\section{References}

1. Al-Ani AN, Flodin L, Söderqvist A, Ackermann P, Samnegård E, Dalén N, Sääf M, Cederholm T, Hedström M. Does rehabilitation matter in patients with femoral neck fracture and cognitive impairment? A prospective study of 246 patients. Arch Phys Med Rehabil. 2010;91(1):51-7.

2. Mitchell R, Harvey L, Brodaty H, Draper B, Close J. Hip fracture and the influence of dementia on health outcomes and access to hospital-based rehabilitation for older individuals. Disabil Rehabil. 2016:1-10.

3. Australian and New Zealand Hip Fracture Registry (ANZHFR) Steering Group. Australian and New Zealand Guideline for Hip Fracture Care-improving outcomes in hip fracture management of adults. Administrative Report. Syndey: Australian and New Zealand Hip Fracture Registry Steering Group; 2014

4. National Institute for Health and Care Excellence. Hip fracture: the management of hip fracture in adults. London: The Royal College of Physicians; 2011.

5. Seitz DP, Adunuri N, Gill SS, Rochon PA. Prevalence of dementia and cognitive impairment among older adults with hip fractures. J Am Med Dir Assoc. 2011;12(8):556-64

6. Chen JS, Sambrook PN, Simpson JM, Cameron ID, Cumming RG, Seibel MJ, Lord SR, March LM. Risk factors for hip fracture among institutionalised older people. Age Ageing. 2009;38(4):429-34.

7. Beaupre LA, Cinats JG, Jones CA, Scharfenberger AV, Johnston DWC, Senthilselvan A, Saunders LD. Does functional recovery in elderly hip fracture patients differ between patients admitted from long-term care and the community? J Gerontol Ser A Biol Med Sci. 2007;62(10):1127-33.

8. Crotty M, Miller M, Whitehead C, Krisnan J, Hearn T. Hip fracture treatmentswhat happens to patients from residential care? J Qual Clin Pract. 2000; 20(4):167-70

9. Neuman MD, Silber JH, Magaziner JS, Passarella MA, Mehta S, Werner RM. Survival and functional outcomes after hip fracture among nursing home residents. JAMA Intern Med. 2014;174(8):1273-80.

10. Sheehan KJ, Fitzgerald L, Hatherley S, Potter C, Ayis S, Martin FC, Gregson $\mathrm{CL}$, Cameron ID, Beaupre LA, Wyatt $\mathrm{D}$, et al. Inequity in rehabilitation interventions after hip fracture: a systematic review. Age Ageing. 2019.

11. Halbert J, Crotty M, Whitehead C, Cameron I, Kurrle S, Graham S, Handoll H, Finnegan T, Jones T, Foley A. Multi-disciplinary rehabilitation after hip 
fracture is associated with improved outcome: a systematic review. J Rehabil Med. 2007;39(7):507-12.

12. Cameron ID. Coordinated multidisciplinary rehabilitation after hip fracture. Disabil Rehabil. 2005:27(18-19):1081-90.

13. Allen J, Koziak A, Buddingh S, Liang J, Buckingham J, Beaupre LA. Rehabilitation in patients with dementia following hip fracture: a systematic review. Physiother Can. 2012;64(2):190-201.

14. Handoll HHG, Cameron ID, Mak JCS, Finnegan TP. Multidisciplinary rehabilitation for older people with hip fractures. Cochrane Database Syst Rev. 2009;4:CD007125.

15. Smith TO, Gilbert AW, Sreekanta A, Sahota O, Griffin XL, Cross JL, Fox C, Lamb SE. Enhanced rehabilitation and care models for adults with dementia following hip fracture surgery. Cochrane Database Syst Rev. 2020;2: CD010569.

16. Crotty M, Killington M, Liu E, Cameron ID, Kurrle S, Kaambwa B, Davies O, Miller M, Chehade M, Ratcliffe J. Should we provide outreach rehabilitation to very old people living in nursing care facilities after a hip fracture? A randomised controlled trial. Age Ageing. 2019;48(3):373-80.

17. South Australian Academic Health Science and Translation Centre. Health System \& Service Reform in South Australia. Adelaide: South Australian Academic Health Science and Translation Centre; 2018. Available at: https:// www.sahealth.sa.gov.au/wps/wcm/connect/46138458-0fb8-425e-93 7eee0d35c93641/FULL+REPORT+-+Health+System+\%26+Service+Reform+ in+South+Australia+Report.pdf?MOD=AJPERES\&CACHEID = ROOTWORKSPACE-46138458-0fb8-425e-937e-ee0d35c93641-n5hHm-n.

18. Street J, Duszynski K, Krawczyk S, Braunack-Mayer A. The use of citizens' juries in health policy decision-making: a systematic review. Soc Sci Med. 2014;109:1-9

19. Parrella A, Braunack-Mayer A, Collins J, Clarke M, Tooher R, Ratcliffe J, Marshall $H$. Prioritizing government funding of adolescent vaccinations: recommendations from young people on a citizens' jury. Vaccine. 2016; 34(31):3592-7.

20. Scuffham, Burton, Kendall, Rixon, Whitty, Ratcliffe, Wilson, Krinks: Engaging the public in healthcare decision making. Citizens' jury on the surgical management of obesity: Methods, processes, and verdicts. 2014.

21. Scuffham MN, Krinks R, Burton P, Whitty JA, Wilson A, Fitzgerald G, Littlejohns P, Kendall E. Engaging the public in healthcare decision-making: Results from a Citizens' Jury on emergency care services. Emerg Med J. 2016;11:782-8

22. Moretto N, Kendall E, Whitty J, Byrnes J, Hills AP, Gordon L, Turkstra E, Scuffham P, Comans T. Yes, the government should tax soft drinks: findings from a citizens' jury in Australia. Int J Environ Res Public Health. 2014;11(3): 2456-71.

23. Department of Health: Buckinghamshire Citizen's Jury Learning and Outcomes Report: Dementia Services. In.; 2011.

24. Laver K, Gnanamanickam E, Whitehead C, Kurrle S, Corlis M, Ratcliffe J, Shulver W, Crotty M. Introducing consumer directed care in residential care settings for older people in Australia: views of a citizens' jury. J Health Serv Res Policy. 2018;23(3):176-84

25. Drummond MF, Sculpher MJ, Claxton K, Stoddart GL, Torrance GW. Methods for the economic evaluation of health care programmes. Oxford: Oxford University Press; 2015.

26. Williams A. Intergenerational equity: an exploration of the'fair innings' argument. Health Econ. 1997;6(2):117-32.

27. Centre J. Citizens jury handbook. Minnesota: The Jefferson Center; 2004

28. Braun V, Clarke V. Using thematic analysis in psychology. Qual Res Psychol. 2006;3(2):77-101.

29. World Health Organization. World Report and Ageing and Health. Geneva: World Health Organization; 2015. Available at: https://www.who.int/ageing/ events/world-report-2015-launch/en/

30. Salkeld G, Cameron I, Cumming R, Easter S, Seymour J, Kurrle S, Quine S. Quality of life related to fear of falling and hip fracture in older women: a time trade off study. BMJ. 2000;320(7231):341.

31. Milte R, Ratcliffe J, Miller M, Whitehead C, Cameron ID, Crotty M. What are frail older people prepared to endure to achieve improved mobility following hip fracture? A discrete choice experiment. J Rehabil Med. 2013; 45(1):81-6.

32. Broad JB, Gott M, Kim H, Boyd M, Chen H, Connolly MJ. Where do people die? An international comparison of the percentage of deaths occurring in hospital and residential aged care settings in 45 populations, using published and available statistics. Int J Public Health. 2013;58(2):257-67.
33. Ko FC, Morrison R. Hip fracture: a trigger for palliative care in vulnerable older adults. JAMA Intern Med. 2014;174(8):1281-2

34. Watts JJ, Abimanyi-Ochom J, Sanders KM: Osteoporosis costing al Australian: a new burden of disease analysis-2012 to 2022. 2013.

35. Lam J, Lord SJ, Hunter KE, Simes RJ, Vu T, Askie LM. Australian clinical trial activity and burden of disease: an analysis of registered trials in national health priority areas. Med J Aust. 2015;203(2):97-101.

36. Network SIG. Management of hip fracture in older people. In: A national clinical guideline. Scotland: NHS Quality Improvement; 2009.

\section{Publisher's Note}

Springer Nature remains neutral with regard to jurisdictional claims in published maps and institutional affiliations.
Ready to submit your research? Choose BMC and benefit from:

- fast, convenient online submission

- thorough peer review by experienced researchers in your field

- rapid publication on acceptance

- support for research data, including large and complex data types

- gold Open Access which fosters wider collaboration and increased citations

- maximum visibility for your research: over $100 \mathrm{M}$ website views per year

At $\mathrm{BMC}$, research is always in progress.

Learn more biomedcentral.com/submissions 